\title{
A pilot peer interview preparation scheme for foundation doctors
}

\author{
Authors: Rachel Campbell, Roisin Campbell, Camille Harron and Keith Gardiner
}

\author{
Aims \\ To improve foundation doctors confidence in approaching job \\ interviews for entry to higher training programmes.
}

\section{Methods}

A peer interview preparation scheme was developed as part of the 'VALUED' strategy at Northern Ireland Medical and Dental Training Agency (NIMDTA). The VALUED strategy aims to develop, support and encourage high-calibre doctors to train and remain in Northern Ireland. We aim to encourage application for higher training, while supporting trainees through the interview process, thereby gaining confidence in approaching their interview for higher training.

The interviewers for the mock interviews were higher level trainees (ST3+). They underwent recruitment and selection training, including equality and diversity training. Training was facilitated by a deanery educationalist and human resources specialist. The foundation trainees completed the interview circuit in pairs allowing them to answer questions and observe and reflect on how others answer questions. They received oral feedback during the process, and written feedback at the end. Alongside this a session was led by faculty on documentation to be brought to interview, portfolio preparation and structuring of interview answers.

\section{Results}

Nine trainees participated in the scheme with eight completing feedback. The scheme assessed trainees' confidence in a variety of domains related to their interview for higher training (Table 1). The Mann-Whitney test was performed to determine whether there was a statistical difference in confidence before and after participation in the scheme. This was demonstrated with a p-value of 0.001 across each of the domains of confidence in approaching the interview, preparing for the interview and in structuring an answer, respectively.

\section{Conclusion}

Trainees partaking in the scheme felt significantly more confident in approaching their specialty interviews after participating in the

Author: Northern Ireland Medical and Dental Training Agency (NIMDTA), Belfast, UK

\begin{tabular}{|c|c|c|}
\hline & $\begin{array}{l}\text { Pre-peer } \\
\text { interview } \\
\text { preparation } \\
\text { average } \\
\text { score (1-10) }\end{array}$ & $\begin{array}{l}\text { Post-peer } \\
\text { interview } \\
\text { preparation } \\
\text { average } \\
\text { score (1-10) }\end{array}$ \\
\hline $\begin{array}{l}\text { How confident are you in } \\
\text { structuring an answer to } \\
\text { interview questions? }\end{array}$ & 4.3 & 7.9 \\
\hline $\begin{array}{l}\text { How confident are you in } \\
\text { preparing for your interview? }\end{array}$ & 4.7 & 8.1 \\
\hline $\begin{array}{l}\text { How confident are you in } \\
\text { approaching your interview? }\end{array}$ & 4.9 & 7.9 \\
\hline $\begin{array}{l}\text { Do you feel the peer interview } \\
\text { scheme was helpful? }\end{array}$ & & 9.5 \\
\hline $\begin{array}{l}\text { Would you recommend this } \\
\text { scheme to your friends applying } \\
\text { for training? }\end{array}$ & & 9.8 \\
\hline
\end{tabular}

scheme. Future plans are to increase the availability of this scheme to foundation doctors, to adapt and extend the scheme to higher level trainees and to ascertain how the scheme has impacted on success in recruitment processes.

\section{Conflict of interest statement}

Nil noted. 